\title{
Multidecadal Sea Level and Gyre Circulation Variability in the Northwestern Tropical Pacific Ocean
}

\author{
Bo QIU AND SHUIMING CHEN \\ Department of Oceanography, University of Hawaii at Manoa, Honolulu, Hawaii
}

(Manuscript received 17 March 2011, in final form 22 July 2011)

\begin{abstract}
Sea level rise with the trend $>10 \mathrm{~mm} \mathrm{yr}^{-1}$ has been observed in the tropical western Pacific Ocean over the 1993-2009 period. This rate is 3 times faster than the global-mean value of the sea level rise. Analyses of the satellite altimeter data and repeat hydrographic data along $137^{\circ} \mathrm{E}$ reveal that this regionally enhanced sea level rise is thermosteric in nature and vertically confined to a patch in the upper ocean above the $12^{\circ} \mathrm{C}$ isotherm. Dynamically, this regional sea level trend is accompanied by southward migration and strengthening of the North Equatorial Current (NEC) and North Equatorial Countercurrent (NECC). Using a 11/2layer reduced-gravity model forced by the ECMWF reanalysis wind stress data, the authors find that both the observed sea level rise and the NEC/NECC's southward migrating and strengthening trends are largely attributable to the upper-ocean water mass redistribution caused by the surface wind stresses of the recently strengthened atmospheric Walker circulation. Based on the long-term model simulation, it is further found that the observed southward migrating and strengthening trends of the NEC and NECC began in the early 1990s. In the two decades prior to 1993, the NEC and NECC had weakened and migrated northward in response to a decrease in the trade winds across the tropical Pacific Ocean.
\end{abstract}

\section{Introduction}

Understanding the global sea level rise has been the focus, as well as a challenge, for many recent investigations of interdisciplinary nature (Church et al. 2004; Bindoff et al. 2007; Willis et al. 2010, and references therein). Although the globally averaged sea level rise has a mean rise at $\sim 3 \mathrm{~mm} \mathrm{yr}^{-1}$ over the past two decades, the regional sea level rise can deviate from this rate significantly. Figure 1, for example, shows the linear trend of sea level rise based on satellite altimeter measurements for the 1993-2010 period. In the broad regions of the tropical western Pacific Ocean, the observed sea level rise trend exceeds $10 \mathrm{~mm} \mathrm{yr}^{-1}$ : that is, more than 3 times the rate of the global-mean sea level rise. Clarifying the causes underlying the regional sea level variability, such as that shown in Fig. 1, has been the subject of numerous studies using data analysis, numerical modeling, and data assimilation techniques (e.g., Carton et al. 2005; Qiu and Chen 2006; Roemmich et al. 2007; Köhl and Stammer 2008; Lee and McPhaden 2008; Timmermann et al. 2010; Feng et al. 2010; Merrifield

Corresponding author address: Dr. Bo Qiu, Department of Oceanography, University of Hawaii at Manoa, 1000 Pope Road, Honolulu, HI 96822.

E-mail: bo@soest.hawaii.edu
2011). A consensus emerging from these studies is that a significant portion of the observed, spatially varying sea level trends reflects the geographical redistribution of upper-ocean water masses (i.e., it involves no changes in the volume of the ocean) and that its primary cause is the low-frequency changes in the surface wind stress field.

It is worth emphasizing that the regional sea level rise is not an isolated phenomenon. Because of the Coriolis force, it is closely tied to the regional upper-ocean circulation changes on the interannual and longer time scales. In the tropical western North Pacific Ocean of interest to this study, the largest sea level rise trend is detected along the band of $8^{\circ}-15^{\circ} \mathrm{N}$ (Fig. 1). This band is where the mean North Equatorial Current (NEC) is located and constitutes the boundary of the wind-driven tropical and subtropical gyres of the North Pacific Ocean. As may be inferred from the mean sea surface height (SSH) map superimposed on Fig. 1, the westward-flowing NEC splits into the northward-flowing Kuroshio and southward-flowing Mindanoa Current after it encounters the Philippine coast. As the enhanced regional sea level rise persists, one may expect a changing circulation trend to appear in the NEC. This, indeed, is the case.

Figure 2a shows the time series of the monthly NEC bifurcation latitude $Y_{b}$ along the Philippine coast estimated 


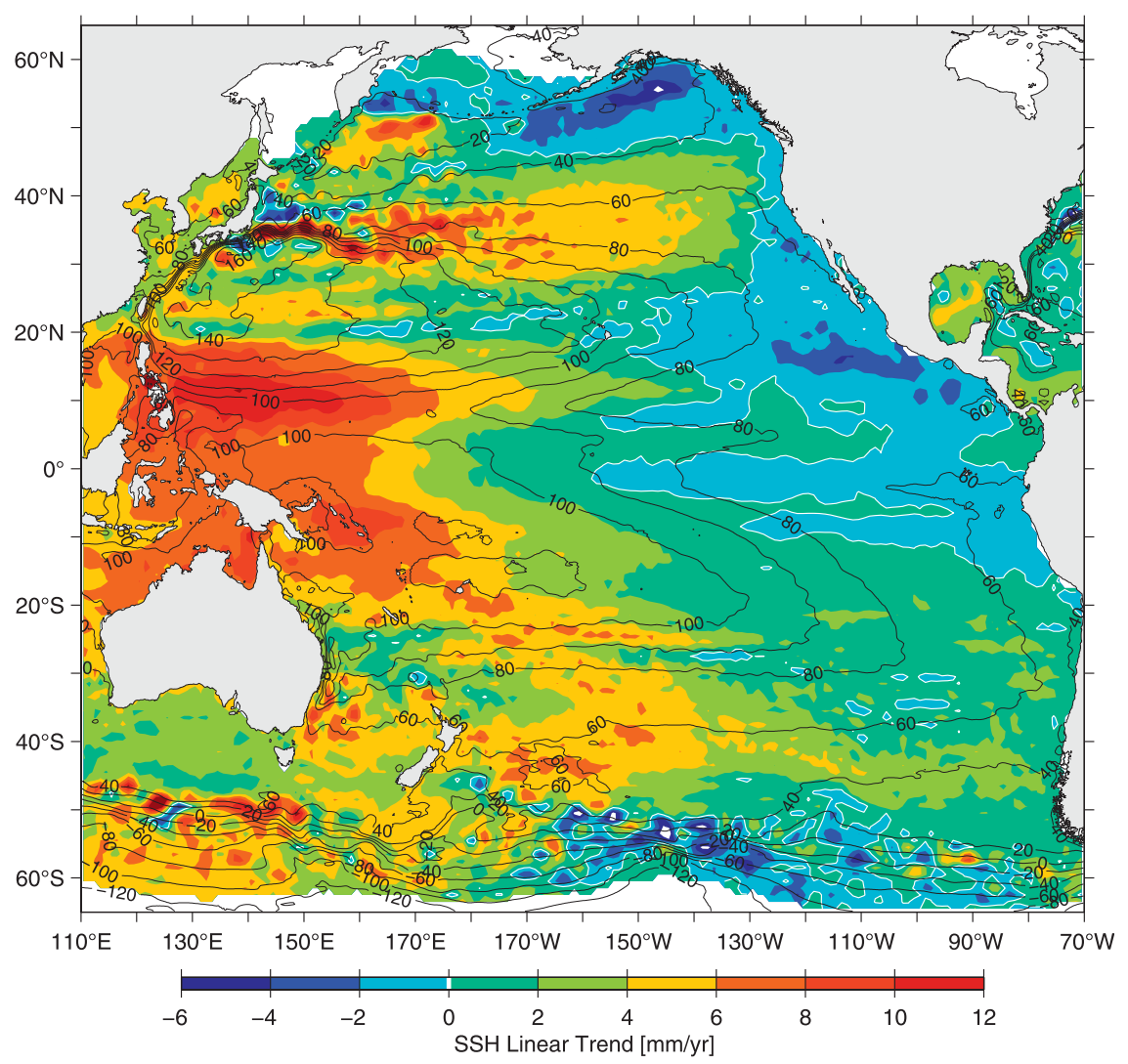

FIG. 1. Linear trend in sea level from the satellite altimeter measurements in 1993-2010. Black contours indicate the mean SSH field $(\mathrm{cm})$ in the Pacific Ocean from Rio et al. (2011).

from the satellite altimeter measurements. Here, $Y_{b}$ is defined at where the meridional velocity is zero within the $2^{\circ}$ band along the Philippine coast (for more details, see Qiu and Chen 2010). On the interannual and longer time scales, the NEC bifurcation latitude delineates the boundary between the wind-driven tropical and subtropical gyres of the North Pacific Ocean and controls the transport partitioning into the Kuroshio and the Mindanao Current (Toole et al. 1988; Lukas et al. 1991; Qiu and Lukas 1996; Kim et al. 2004). The $Y_{b}$ time series in Fig. 2a is composed of variability with time scales ranging from intraseasonal to decadal. For the interannual and longer time-scale variability, one can readily identify the changes relating to the El NiñoSouthern Oscillation (ENSO) events as represented by the Niño-3.4 index (Fig. 2b). Aside from this ENSOforced variability, Fig. 2a reveals that the NEC bifurcation has occurred progressively at a southern latitude over the past 18 yr. As indicated by the dashed line in Fig. 2a, the southward migration has a mean rate of $-0.112^{\circ}$ latitude per year. Although the SSH trend in Fig. 1 exhibits a pattern reminiscent of La Niña conditions, it is important to note that much of the NEC's migration trend shown in
Fig. 2a is not due to the random occurrence of the interannual ENSO events. The $Y_{b}$ time series, after regressing out the Niño-3.4 index, has a similar, mean migration rate of $-0.092^{\circ}$ latitude per year. Integrated over the past $18 \mathrm{yr}$, the NEC bifurcation point has migrated southward by $2^{\circ}$ latitude. Compared to the $10^{\circ}$ width of the wind-driven tropical gyre in the North Pacific Ocean, this $2^{\circ}$ migration by the NEC represents a substantial fractional change.

The southward migrating trend in the NEC bifurcation reflects only one aspect of the circulation changes in the western tropical North Pacific Ocean. Other important circulation features in the region with a large sea level rise trend in the western tropical North Pacific Ocean (roughly $0^{\circ}-20^{\circ} \mathrm{N}$ and $120^{\circ}-170^{\circ} \mathrm{E}$; see Fig. 1) include the westward-flowing NEC and the eastward-flowing North Equatorial Countercurrent (NECC). With the use of available satellite altimeters, we will first describe in this study the circulation and transport changes of both the NEC and NECC in a comprehensive way (section 2). By analyzing the long-term repeat hydrographic data along the $137^{\circ} \mathrm{E}$ meridian, we attempt to clarify not only the surface signals but also the vertical structures 

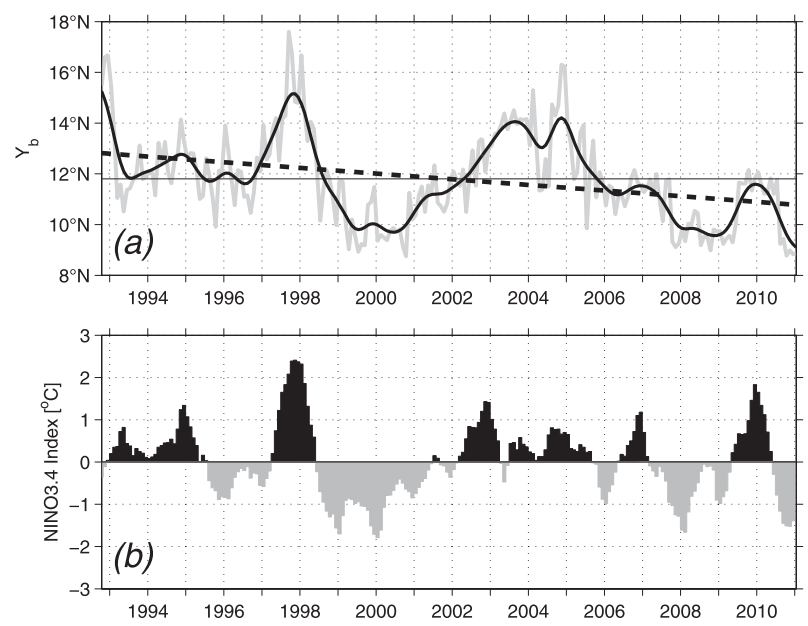

FIG. 2. (a) Time series of the NEC bifurcation latitude $Y_{b}$ inferred from the monthly satellite altimeter SSH data (gray line). Black solid line indicates the low-pass-filtered time series, and the dashed line indicates the linear trend. As detailed in Qiu and Chen (2010), $Y_{b}$ is defined as where the altimeter-derived meridional surface velocity averaged within the $2^{\circ}$ band along the Philippine coast equals zero. (b) Time series of the Niño-3.4 index.

of the observed circulation and transport changes (section 3). After clarifying their vertical structures, we adopt a $1 \frac{1}{2}$-layer reduced-gravity model to examine the NEC and NECC changes both before and after the satellite altimeter data become available (section 4). Based on the longer time series from the model, we work to elucidate the roles played by the surface wind stress forcing in causing the trend reversal in the NEC and NECC variability at the beginning of the 1990s (section 5).

\section{Altimeter data analyses}

To examine the circulation changes in the tropical western Pacific Ocean, we use the global SSH anomaly dataset compiled by the Collecte Localisation Satellites (CLS) Space Oceanographic Division of Toulouse, France. The dataset merges the along-track SSH measurements from all satellite altimeter missions and has a 7-day temporal resolution and a $1 / 3^{\circ}$ longitude Mercator spatial resolution (Le Traon et al. 1998; Ducet et al. 2000). To be consistent with the available hydrographic and surface wind stress data used in later sections, we focus our analysis of altimeter data to the period from October 1992 through December 2009.

To quantify the circulation changes associated with the NEC and NECC, we examine first their transport signals by combining the SSH anomaly data with the upper-layer thickness data,

$$
\begin{aligned}
& T_{\mathrm{NEC}-\mathrm{N}} \equiv-\frac{1}{L_{x}} \int_{130^{\circ} \mathrm{E}}^{160^{\circ} \mathrm{E}} \int_{Y_{b}}^{18^{\circ} \mathrm{N}} u(x, y, t) H(x, y, t) d y d x \\
& T_{\mathrm{NEC}-\mathrm{S}} \equiv-\frac{1}{L_{x}} \int_{130^{\circ} \mathrm{E}}^{160^{\circ} \mathrm{E}} \int_{Y_{c}}^{Y_{b}} u(x, y, t) H(x, y, t) d y d x, \text { and } \\
& T_{\mathrm{NECC}} \equiv \frac{1}{L_{x}} \int_{130^{\circ} \mathrm{E}}^{160^{\circ} \mathrm{E}} \int_{2^{\circ} \mathrm{N}}^{Y_{c}} u(x, y, t) H(x, y, t) d y d x
\end{aligned}
$$

where $T_{\mathrm{NEC}-\mathrm{N}}$ denotes the westward NEC transport north of the gyre boundary, or that part of the NEC entering into the North Pacific subtropical gyre. As noted in the introduction, the gyre boundary here is given by the interannually varying NEC bifurcation latitude $Y_{b}$ (i.e., the black line in Fig. 2a). The terms $T_{\mathrm{NEC}-\mathrm{S}}$ and $T_{\mathrm{NECC}}$ in Eq. (1) denote the NEC and NECC transport within the tropical gyre, respectively, and $Y_{c}$ denotes the latitude separating the westward-flowing NEC from the eastwardflowing NECC. Selection of $2^{\circ} \mathrm{N}$ as the southern boundary for the NECC is based on observations presented in Qiu and Joyce (1992), Yu et al. (2000), and Kashino et al. (2009).

In Eq. (1), $H$ denotes the upper-ocean layer thickness and is given by

$$
H(x, y, t)=\bar{H}(x, y)+\frac{g}{g^{\prime}} h^{\prime}(x, y, t),
$$

where $\bar{H}(x, y)$ is the mean upper-ocean layer thickness and is derived in this study as the layer above the $12^{\circ} \mathrm{C}$ isotherm from the World Ocean Atlas 2009 (Locarnini et al. 2010; see Fig. 3). The choice of using the $12^{\circ} \mathrm{C}$ isotherm to represent the upper-ocean layer thickness follows many previous studies that examined the variability of the tropical Pacific Ocean (e.g., Kessler 1990; Capotondi and Alexander 2001). The second term on the RHS of Eq. (2) represents the time-varying upper-ocean layer thickness anomaly signal $H^{\prime}(x, y, t)$, and it is calculated in this study by adopting the $1 \frac{1}{2}$-layer reduced-gravity dynamics, $g h^{\prime}(x, y, t)=g^{\prime} H^{\prime}(x, y, t)$, where $g^{\prime}=0.03 \mathrm{~m} \mathrm{~s}^{-2}$ is the reduced-gravity constant and $h^{\prime}(x, y, t)$ is the altimeterderived SSH anomaly data. The validity of the $1 \frac{1}{2} 2$-layer reduced-gravity dynamics is assessed quantitatively in section 3 when we examine the vertical structure of the NEC/ NECC variability using repeat hydrographic data. From geostrophy, the zonal velocity $u(x, y, t)$ in Eq. (1) is determined by

$$
u(x, y, t)=-\frac{g}{f} \frac{\partial}{\partial y}\left[\bar{h}(x, y)+h^{\prime}(x, y, t)\right]
$$




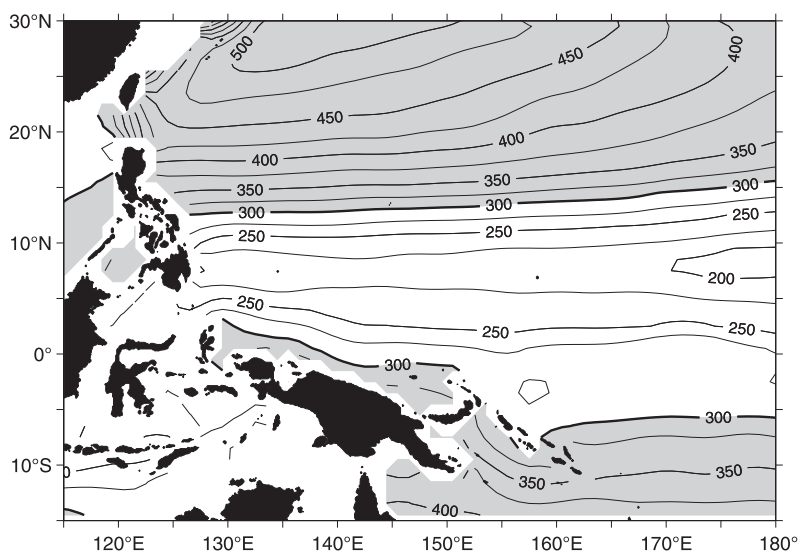

FIG. 3. Climatological upper-ocean layer thickness $\bar{H}(x, y)$ distribution (unit in meters) in the tropical western Pacific Ocean. Here, the upper-ocean layer thickness is defined as the thickness above the $12^{\circ} \mathrm{C}$ isotherm based on the World Ocean Atlas 2009 climatology (Locarnini et al. 2010). Areas thicker than $300 \mathrm{~m}$ are shaded.

where $f$ is the Coriolis parameter and $\bar{h}(x, y)$ is the mean SSH shown in Fig. 1. To capture the broad-scale changes, all transport values to be presented are zonally averaged over $L_{x}$ from $130^{\circ}$ to $160^{\circ} \mathrm{E}$.

Figure 4a shows the time series of the NEC transport circulating in the subtropical gyre $T_{\mathrm{NEC}-\mathrm{N}}$. Like the $Y_{b}$ time series shown in Fig. $2 \mathrm{a}$, it contains variability of multiple time scales and a prominent long-term trend. Relative to the mean transport value of $\sim 20 \mathrm{~Sv}(1 \mathrm{~Sv} \equiv$ $\left.10^{6} \mathrm{~m}^{3} \mathrm{~s}^{-1}\right), T_{\mathrm{NEC}-\mathrm{N}}$ increased by $7.1 \mathrm{~Sv}$, or a $35 \%$ increase, over the 1993-2009 period. On the interannual time scales, changes in $T_{\mathrm{NEC-N}}$ tend to follow the Niño-3.4 index (Fig. 2b); a maximum linear correlation $(r=0.61)$ is obtained when the detrended $T_{\mathrm{NEC}-\mathrm{N}}$ time series lags the Niño-3.4 index by 9 months.

Within the tropical gyre, large seasonal variations are seen in the NEC transport and gyre center latitude time series of Figs. 4b,c. In concert with the southward (northward) migration of $Y_{c}$ in summer (winter), the NEC transport $T_{\mathrm{NEC}-\mathrm{S}}$ tends to increase (decrease). Seasonal variations are less obvious in the NECC transport time series (Fig. 4d). Similar to the trend in the NEC bifurcation latitude, Fig. 4c reveals a persistent southward migration in the center of the tropical gyre: over the 1993-2009 period, $Y_{c}$ shifted southward from $7.5^{\circ}$ to $6.5^{\circ} \mathrm{N}$. This $1^{\circ}$ southward migration by the center of the tropical gyre is smaller in amplitude than that of $Y_{b}$, and it is consistent with the fact that the sea level rise signals have greater amplitudes along the tropical-subtropical gyre boundary of $\sim 12^{\circ} \mathrm{N}$ than along the $7^{\circ} \mathrm{N}$ latitude of the tropical gyre center (recall Fig. 1). Compared to the trend for $T_{\mathrm{NEC}-\mathrm{N}}$, the increase of the trend for the westward NEC transport in the tropical gyre is weaker,
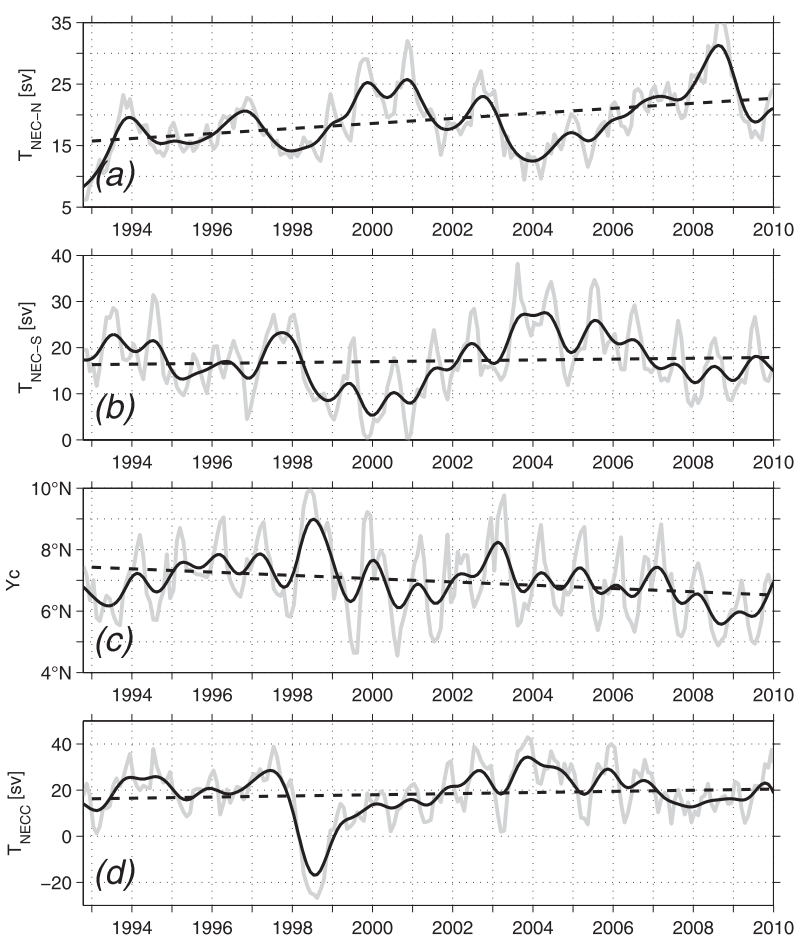

FIG. 4. Time series of (a) the NEC transport circulating in the subtropical gyre, (b) the NEC transport circulating in the tropical gyre, (c) the center latitude of the tropical gyre, and (d) the NECC transport based on the satellite altimeter measurements. In all plots, the gray line denotes the monthly values, the black line denotes the low-pass-filtered time series (with a cutoff period at 6 months), and the dashed line denotes the linear trend.

measuring 1.6 Sv over the 1993-2009 period. Finally, the increase of the trend in $T_{\mathrm{NECC}}$ is at $4.1 \mathrm{~Sv}$ over the past $17 \mathrm{yr}$.

The results shown above in Fig. 4 have all been spatially averaged. To gain an insight into the spatial patterns in the long-term NEC and NECC changes, we plot in Fig. 5 the linear trend of $u H(x, y, t)$ as a function of $x$ and $y$ over the 1993-2009 period. In the tropical region, $u H$ has by and large a zonally coherent increasing trend south of $5^{\circ} \mathrm{N}$ and a decreasing trend between $5^{\circ}$ and $12.5^{\circ} \mathrm{N}$. With the center of the tropical gyre located at $\sim 7^{\circ} \mathrm{N}$, these opposing trends straddling $5^{\circ} \mathrm{N}$ correspond to the long-term southward migration by the tropic gyre discussed above. When combined, the NEC transport (i.e., $T_{\mathrm{NEC}-\mathrm{N}}+T_{\mathrm{NEC}-\mathrm{S}}$ in Fig. 4 ) shows an increase of 8.3 Sv over the 1993-2009 period. From Fig. 5, it is clear that this increasing trend is mostly due to the intensification of the NEC in the latitude band south of $12.5^{\circ} \mathrm{N}$. In the northern NEC band between $12.5^{\circ}$ and $18^{\circ} \mathrm{N}$, the $u H$ trends have meridionally alternating signs and their integrated effect is to slightly weaken the westward-flowing NEC over the past $17 \mathrm{yr}$. 


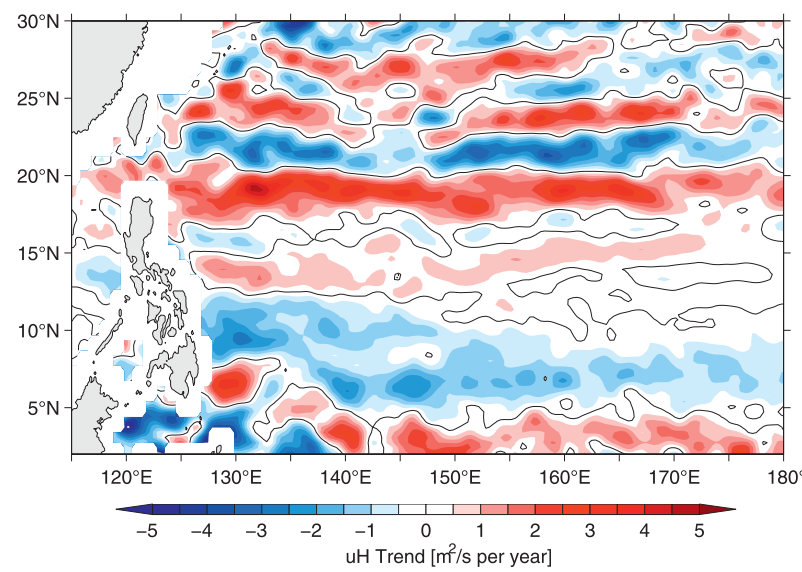

FIG. 5. Linear trend in the zonal transport $u H$ field over the 1993-2009 period based on the satellite altimeter measurements. See Eqs. (2) and (3) for the $u$ and $H$ definitions. Black contours denote the trend of $u H$ equals zero.

Farther north at $18^{\circ}-21^{\circ} \mathrm{N}$, a zonal band with positive $u H$ trend stands out. Its existence signifies that the increased NEC transport north of $Y_{b}$ (i.e., $T_{\mathrm{NEC}-\mathrm{N}}$ in Fig. 4a) largely recirculates offshore along this band. In other words, the effect of the enhanced NEC is limited to the upstream Kuroshio to about the Luzon Strait. Consistent with this result, an examination of the Sverdrup streamfunction trend in the 1993-2009 period reveals that the wind-driven subtropical gyre strengthened in the band south of $22^{\circ} \mathrm{N}$ but weakened north of $22^{\circ} \mathrm{N}$ (figure not shown).

\section{Repeat hydrographic data analyses}

In examining the NEC-NECC variability in the tropical western Pacific Ocean in the preceding section, we combined satellite altimeter SSH with climatological temperature data and adopted the assumption of $1 \frac{1}{2}$-layer reduced-gravity dynamics. To what extent is this assumption valid? Equally important, what are the vertical structures associated with the linear trend changes in the NEC and NECC described in section 2? In terms of the sea level rise trend in the tropical north western Pacific Ocean shown in Fig. 1, do the salinity signals contribute as much as the temperature signals?

To answer these questions, we analyze in this section temperature-salinity $(T-S)$ data from the repeat hydrographic surveys by the Japan Meteorological Agency (JMA) along the $137^{\circ} \mathrm{E}$ meridian. The surveys traverse from the coast of Japan at $34^{\circ} \mathrm{N}$ to offshore of New Guinea at $3^{\circ} \mathrm{N}$ and have a nominal $1^{\circ}$ latitude spatial resolution. Since 1992, JMA has carried out four repeat surveys per year, and the quarterly hydrographic data from 1993 to 2009 are used in our analyses. To provide

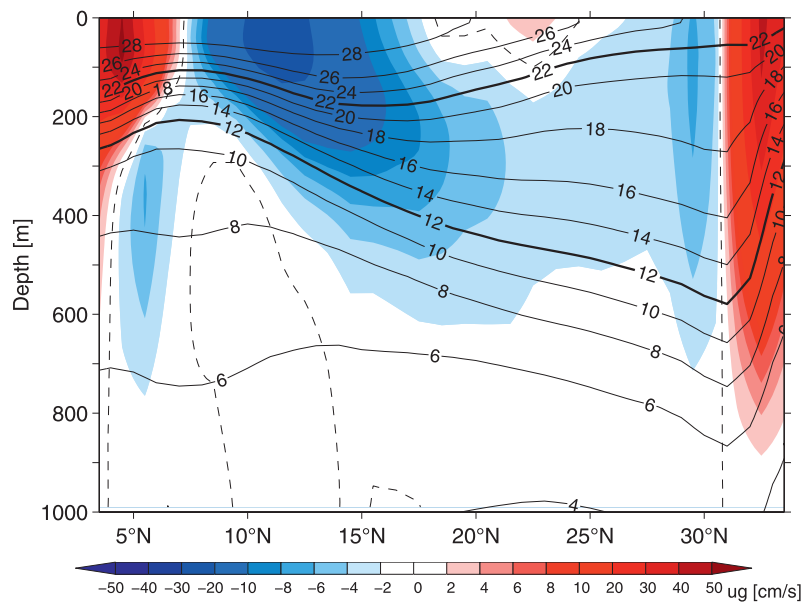

FIG. 6. Mean latitude-depth section of temperature (solid contours) and zonal geostrophic velocity (color shading) along $137^{\circ} \mathrm{E}$ from the JMA repeat hydrographic surveys of 1993-2009. The geostrophic velocity is referenced to 1000 dbar and dashed lines denote the zero velocity contours. Notice that the color shading scale is nonlinear.

a context to the trend signals explored below, we plot in Fig. 6 the latitude-depth section of time-mean temperature and zonal geostrophic velocity from the 1993-2009 surveys. The main body of the westward-flowing NEC, existing between $7^{\circ}$ and $18^{\circ} \mathrm{N},{ }^{1}$ is fully resolved by the hydrographic surveys. With the southernmost hydrographic cast at $3^{\circ} \mathrm{N}$, however, estimating the zonal geostrophic velocity only extends to $3.5^{\circ} \mathrm{N}$, and this can result in an underestimation for the NECC transport (by $\sim 2 \mathrm{~Sv}$ based on the altimeter data analysis in section 2). To be consistent with the results in the previous section, the transport values for NEC and NECC based on the hydrographic data below are calculated in the upper ocean above the $12^{\circ} \mathrm{C}$ isotherm. As indicated in Fig. 6, choosing the $12^{\circ} \mathrm{C}$ isotherm as the base for the NECC transport calculation avoids contamination from the eastwardflowing Northern Subsurface Countercurrent (i.e., the Tsuchiya jet; Tsuchiya 1975) that exists equatorward beneath the NECC. Examining the Tsuchiya jet variability requires, at least, a $2 \frac{1}{2}$-layer reduced-gravity model and is beyond the scope of this study.

\footnotetext{
${ }^{1}$ North of $18^{\circ} \mathrm{N}$ in the western North Pacific Ocean exists the shallow eastward-flowing Subtropical Countercurrent. Because of the vertical shear between the NEC and Subtropical Countercurrent, the $18^{\circ}-25^{\circ} \mathrm{N}$ band is one of the most eddy-rich regions in the Pacific Ocean (Qiu 1999; Roemmich and Gilson 2001; Kobashi and Kawamura 2002). As defined in Eqs. (1a) and (4), this band, for which the 1/1/2-layer reduced-gravity dynamics is inadequate, is intentionally excluded from the $T_{\mathrm{NEC}-\mathrm{N}}$ evaluation.
} 
Figure 7 shows the time series for $T_{\mathrm{NEC}-\mathrm{N}}, T_{\mathrm{NEC}-\mathrm{S}}, Y_{c}$, and $T_{\mathrm{NECC}}$ based on the quarterly hydrographic data. Following Eq. (1), we define

$$
T_{\text {NEC-N }} \equiv-\int_{Y_{b}}^{18^{\circ} \mathrm{N}} \int_{12^{\circ} \mathrm{C}}^{\text {surface }} u_{g}(y, z, t) d z d y,
$$

where $u_{g}(y, z, t)$ denotes the zonal geostrophic velocity estimated from the hydrographic data with a reference depth at 1000 dbar. Similar definitions are adopted for calculating $T_{\mathrm{NEC}-\mathrm{S}}$ and $T_{\mathrm{NECC}}$. Because these transport and $Y_{c}$ evaluations are based on individual cruise data along a single longitude $\left(137^{\circ} \mathrm{E}\right)$, the signals in Fig. 7 appear less smooth than those presented in Fig. 4. Nevertheless, key features regarding the linear trends are in agreement between these two independent estimates from the hydrographic and altimeter measurements. For example, Fig. 7a reveals there is a significant increase in $T_{\mathrm{NEC}-\mathrm{N}}$ at the rate of $\sim 10 \mathrm{~Sv}$ over the 1993-2009 period. A similar increasing trend is also seen in Fig. 4a, although the rate in Fig. $4 \mathrm{a}$ is somewhat smaller at $\sim 7 \mathrm{~Sv}$ over the same period. For $T_{\mathrm{NEC}-\mathrm{S}}$, Fig. $7 \mathrm{~b}$ indicates a weak, decreasing trend of $2.4 \mathrm{~Sv}$ over the 1993-2009 period. Although such a decreasing trend is absent in Fig. 4b, it is important to note that the sum of the NEC transport, $T_{\text {NEC-N }}+T_{\text {NEC-S }}$, in Figs. 4 and 7 has a similar increasing rate of $\sim 8 \mathrm{~Sv}$ over the 1993-2009 period. For the center latitude of the tropical gyre $Y_{c}$, Fig. 7c reveals a southward migration of about $1^{\circ}$ in the 1993-2009 period, a trend very similar to that detected in Fig. $4 \mathrm{c}$ from the altimeter data.

For the long-term NECC transport changes, Fig. 7d shows the presence of a weak decreasing trend of $-1.6 \mathrm{~Sv}$ over the 1993-2009 period. At first glance, this decreasing trend appears to contradict the $4.1 \mathrm{~Sv}(17 \mathrm{yr})^{-1}$ increasing trend revealed in Fig. 4d. A close inspection of Fig. 5, however, indicates that this discrepancy is likely due to the fact that the hydrographic surveys along $137^{\circ} \mathrm{E}$ occupied a region north of New Guinea where $u H$ has a localized negative trend that is opposite in sign to the $T_{\mathrm{NECC}}$ trend averaged zonally from $130^{\circ}$ to $160^{\circ} \mathrm{E}$.

In addition to examining the transport changes presented in Fig. 7, the repeat hydrographic surveys along $137^{\circ} \mathrm{E}$ also provide us with a unique opportunity to clarify the internal structures associated with the linear trend in the observed circulation and sea level changes. As shown in Fig. 1 , the $137^{\circ} \mathrm{E}$ meridian traverses the center of the regional sea level rise maximum and is thus likely to be representative of the changing signals in the entire northwestern tropical Pacific Ocean. Figures 8a,b show the linear trend in $T$ and $S$ as a function of depth and latitude along $137^{\circ} \mathrm{E}$ over the 1993-2009 period. In both the $T$ and $S$ fields, a clear sign reversal exists near $18^{\circ} \mathrm{N}$
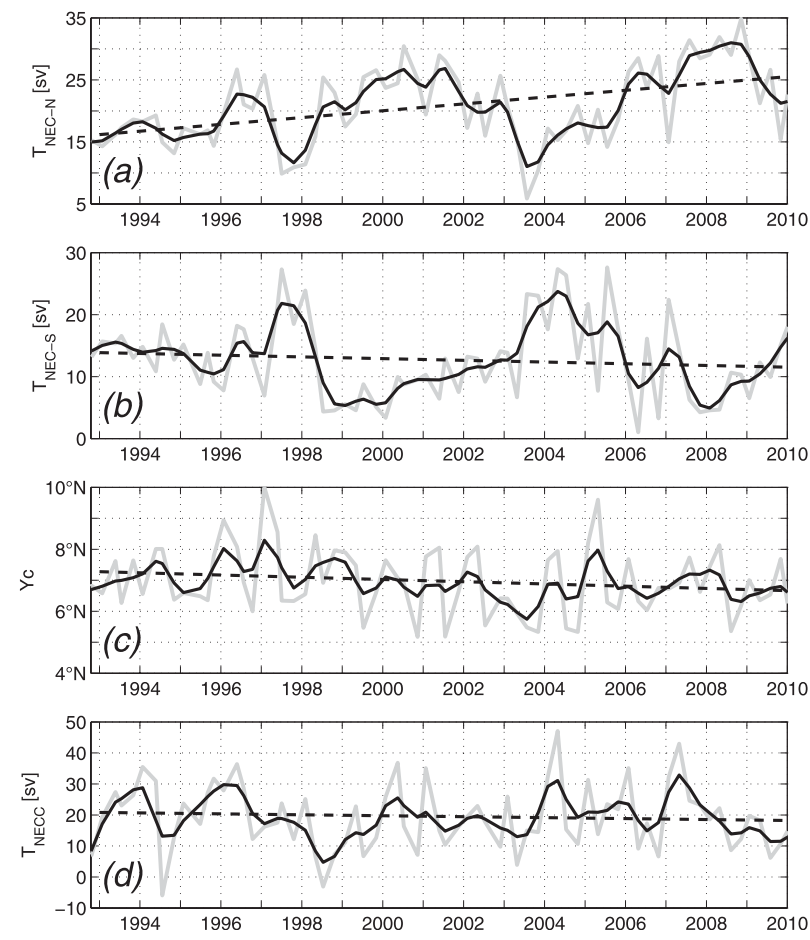

FIG. 7. As in Fig. 4, but based on the quarterly JMA repeat hydrographic surveys along $137^{\circ} \mathrm{E}$. In all plots, the gray line denotes the quarterly values, the black line denotes the low-pass-filtered time series (with a cutoff period at 6 months), and the dashed line denotes the linear trend.

along the northern edge of the NEC. South of $\sim 18^{\circ} \mathrm{N}$, broad-scale warming and salinification trends appear mostly in the upper ocean above the $12^{\circ} \mathrm{C}$ isotherm. These warming and salinification trends reflect in part the southward migration of the tropical gyre, which brings warmer and saline NEC water southward. As will be discussed in section 4 , the second reason for the positive $T$ and $S$ trend south of $18^{\circ} \mathrm{N}$ is the deepening of the upper layer associated with the wind-driven Ekman flux convergence. Notice that this deepening effect is not independent from the effect of the gyre migration because the wind stress forcing induces both the lateral and vertical changes in the tropical gyre. Plotting the $\theta-S$ diagrams south of $18^{\circ} \mathrm{N}$ reveals that little change occurred in the $\theta-S$ relations for the periods of the 1990 s versus the 2000s (Fig. 9). This confirms the notion that the linear trend temperature and salinity changes in the tropical region largely reflect the coherent movement of isopycnals rather than additional heat and freshwater input to the temperature and salinity field.

In contrast to the tropics, the salinity field shows a broad-scale freshening trend north of $18^{\circ} \mathrm{N}$. The trend is again largely confined to above the $12^{\circ} \mathrm{C}$ isotherm. The temperature trend north of $18^{\circ} \mathrm{N}$ has a laterally 
(a) Temperature Trend along $137^{\circ} \mathrm{E}\left[{ }^{\circ} \mathrm{C} / \mathrm{yr}\right]: 1993-2009$

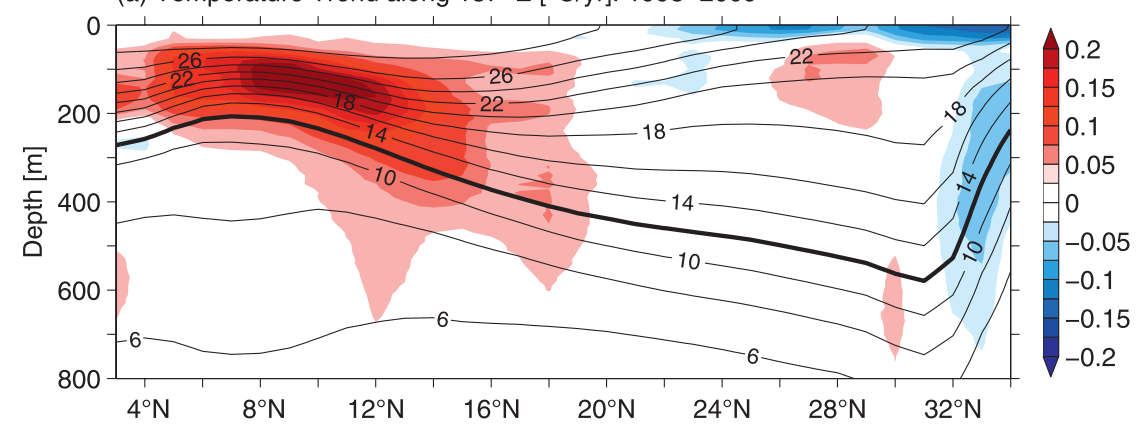

(b) Salinity Trend along $137^{\circ} \mathrm{E}$ [PSU/yr]: 1993-2009

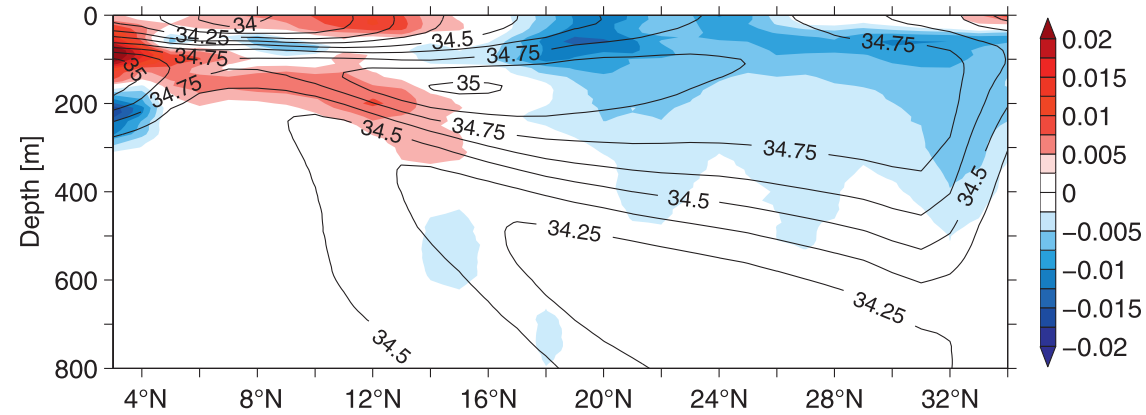

(c) SSH Trend along $137^{\circ} \mathrm{E}: 1993-2009$

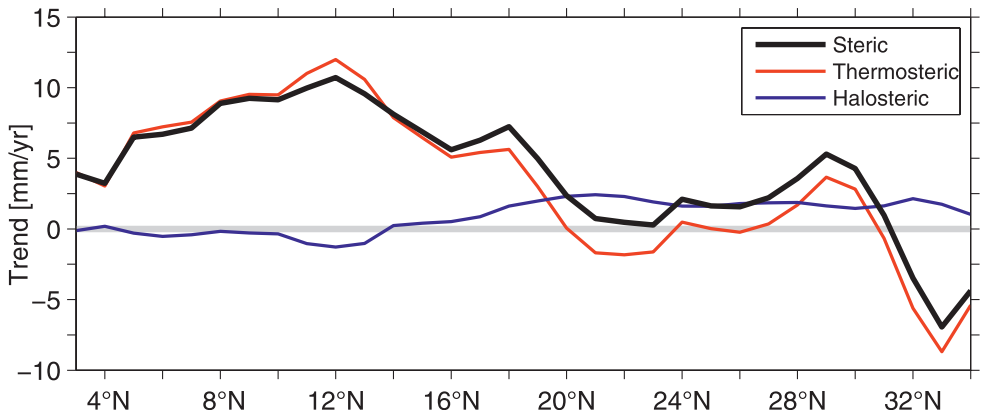

FIG. 8. (a) Linear trend in temperature (color shading) as a function of depth and latitude along $137^{\circ} \mathrm{E}$ over the $1993-2009$ period. Contours show the mean temperature distribution of 1993-2009. (b) As in (a), but for the salinity field. (c) Steric SSH trend (black line) along $137^{\circ} \mathrm{E}$ over the 1993-2009 period. The red (blue) line denotes the thermosteric (halosteric) component of the steric SSH trend. All SSH signals are calculated relative to the 1000-dbar depth.

inhomogeneous pattern: although a uniform cooling trend appears throughout in the surface layer, vertically coherent warming and cooling trends are seen in the bands of $25^{\circ}-31^{\circ} \mathrm{N}$ and north of $31^{\circ} \mathrm{N}$, respectively. These dipolar temperature trends reflect the southward shift of the Kuroshio jet across $137^{\circ} \mathrm{E}$ in the past $17 \mathrm{yr}$.

The correlated temperature and salinity trends in Figs. 8a,b point to their opposing roles in generating the steric sea level trend. To quantify the relative contributions from the $T$ and $S$ signals, we decompose in Fig. $8 \mathrm{c}$ the steric sea level trend of 1993-2009 from the observed $T-S$ data along $137^{\circ} \mathrm{E}$ (black curve) into the thermosteric (red curve) versus halosteric (blue curve) components. Here, the reference level for calculating sea level is set at 1000 dbar and the thermosteric and halosteric decompositions are done by replacing the timevarying $S(y, z, t)$ and $T(y, z, t)$ by their time-mean values $\bar{S}(y, z)$ and $\bar{T}(y, z)$ in the 1993-2009 period, respectively. In the region south of $18^{\circ} \mathrm{N}$, the steric sea level trend is mostly controlled by the thermosteric component, which explains $88 \%$ of the total steric trend variance. Although the halosteric component has a larger and spatially uniform value north of $18^{\circ} \mathrm{N}$, the spatially modulating steric sea level trend signals there are nevertheless dictated by the thermosteric signals. The result of the steric sea level trend being dominated by the thermosteric component is consistent with findings by Köhl and Stammer (2008) based on data assimilation synthesis. 


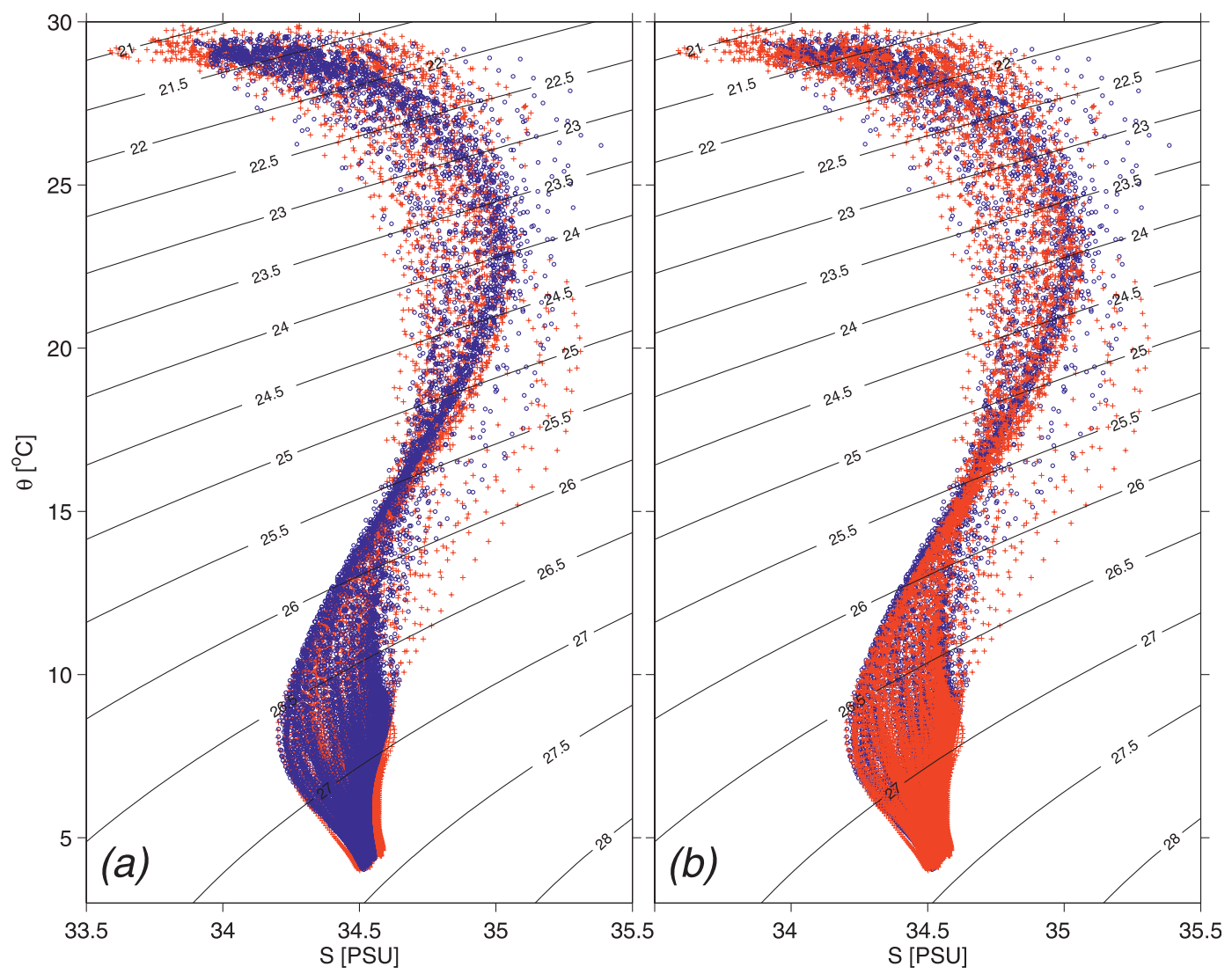

FIG. 9. $\theta-S$ relations from the JMA hydrographic data along $137^{\circ} \mathrm{E}$ between $3^{\circ}$ and $17^{\circ} \mathrm{N}$. (a) $\theta-S$ data of $2002-09$ (blue dots) superimposed over those of 1993-2000 (red crosses). (b) $\theta-S$ data of 1993-2000 (red crosses) superimposed over those of 2002-09 (blue dots).

\section{Forcing of the multidecadal trend signals}

With the observed temperature and salinity trend signals confined vertically coherently to the upper ocean above the $12^{\circ} \mathrm{C}$ isotherm, the result of Fig. 8 validates the assumption of the 1/2/2-layer reduced-gravity dynamics in the northwestern tropical Pacific Ocean, the region of interest to this study. In this section, we seek to clarify the causes responsible for the observed sea level and circulation trends by adopting a nonlinear $1 \frac{1}{2}$-layer reduced-gravity model for the Pacific Ocean. The equations governing the upper-ocean motion in the $1 \frac{1}{2}$-layer reduced-gravity system are

$$
\begin{aligned}
\frac{\partial \mathbf{u}}{\partial t}+\zeta \mathbf{k} \times \mathbf{u} & =-\nabla E+A_{h} \nabla^{2} \mathbf{u}+\frac{\boldsymbol{\tau}}{\rho_{o} H} \text { and } \\
\frac{\partial H}{\partial t}+\nabla \cdot(H \mathbf{u}) & =0
\end{aligned}
$$

where $\zeta=f+\mathbf{k} \cdot \boldsymbol{\nabla} \times \mathbf{u}$ denotes the absolute vorticity and $E=g^{\prime} H+\left(u^{2}+v^{2}\right) / 2$ is the total energy. In Eqs. (5) and $(6), \mathbf{u}=(u, v)$ is the horizontal velocity vector, $\boldsymbol{\tau}$ is the surface wind stress vector, $H$ is the time-varying upper-ocean layer thickness, $\rho_{o}$ is the reference density, and $A_{h}$ is the horizontal eddy viscosity coefficient. For the present study, we set the model domain to be $30^{\circ} \mathrm{S}-40^{\circ} \mathrm{N}$ and $105^{\circ} \mathrm{E}-70^{\circ} \mathrm{W}$ and force the model ocean using the monthly wind stress data of 1959-2009 from the European Center for Medium-Range Weather Forecasts (ECMWF) Ocean Analysis System ORA-S3 (Balmaseda et al. 2008). The model is initialized with a uniform layer thickness of $300 \mathrm{~m}$ and has parameter values $g^{\prime}=0.03 \mathrm{~m} \mathrm{~s}^{-2}$ and $A_{h}=$ $1000 \mathrm{~m}^{2} \mathrm{~s}^{-1}$. Because it takes the model ocean $\sim 12 \mathrm{yr}$ to spin up and reach the quasi-equilibrium state, we confine our analysis of the model output below to the period of 1972-2009.

Figure 10 compares the linear sea level trend derived from the model versus the satellite altimeter measurements for the 1993-2009 period. Because the model ocean conserves the total water mass, we have subtracted the $3.2 \mathrm{~mm} \mathrm{yr}^{-1}$ global-mean sea level rise value (Willis et al. 2010) from the altimeter-derived trend for a more direct comparison. The modeled trend exhibits a spatial pattern and amplitude very similar to those from the adjusted 
(a)

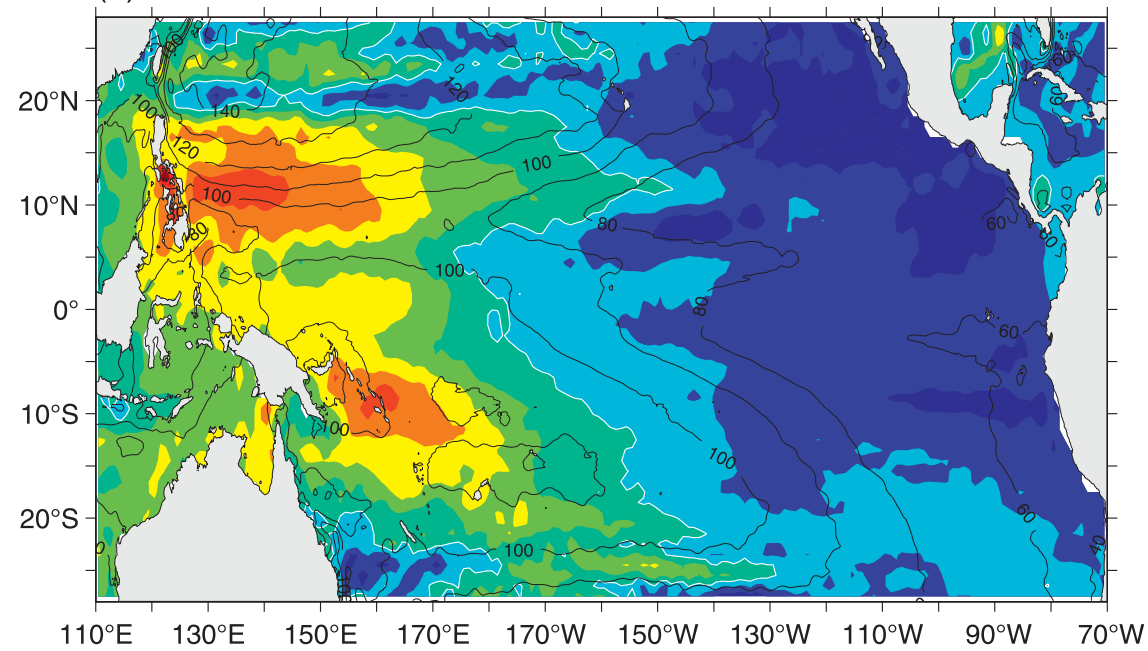

(b)

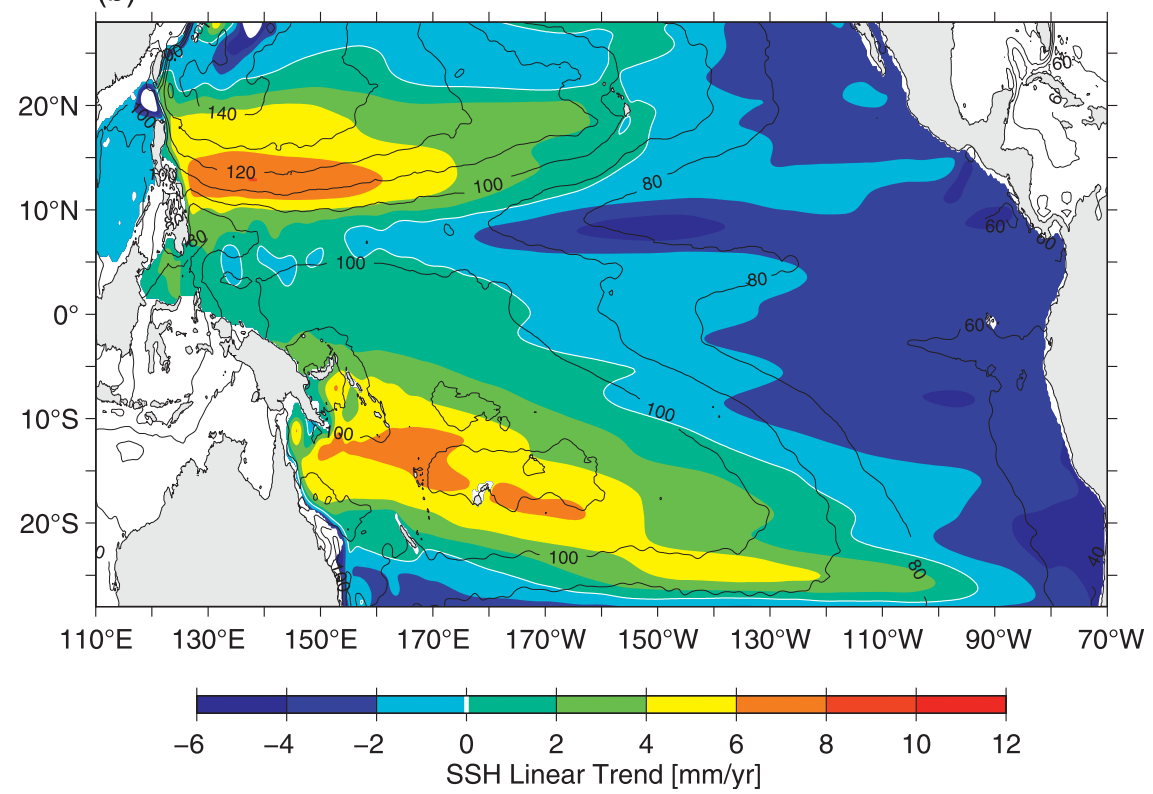

FIG. 10. (a) Linear trend in SSH in 1993-2009 derived from the satellite altimeter measurements after removal of the global-mean sea level rise trend of $3.2 \mathrm{~mm} \mathrm{yr}^{-1}$. (b) As in (a), but derived from the wind-driven 1 $1 \frac{1}{2}$-layer reduced-gravity model. White contours denote the zero linear trend lines, and black contours indicate the mean SSH field $(\mathrm{cm})$ in the Pacific Ocean from Rio et al. (2011).

altimeter data, indicating that the spatially varying sea level trend in the tropical and subtropical Pacific Ocean reflects largely the water mass redistribution forced by the changing surface wind stresses. In addition to the sea level trend, the model also performs well in simulating the time-varying SSH signals in the tropical band of $18^{\circ}$ latitude, where the modeled and observed SSH time series have an overall linear correlation exceeding 0.5 (Fig. 11). These model results are consistent with those obtained by Timmermann et al. (2010), who have used a wind-forced 11/2-layer reduced-gravity model similar to that used in this study.

Using the model output for $u H$ and following the same definitions listed in Eq. (1), we plot in Fig. 12 the time series of $T_{\mathrm{NEC}-\mathrm{N}}, T_{\mathrm{NEC}-\mathrm{S}}, Y_{c}$, and $T_{\mathrm{NECC}}$ for the period of 1973-2009. For the last 17 yr during which comparisons with the satellite altimeter results have been possible (see the shaded period in Fig. 12), the modeled NEC and NECC changes show trends very similar to those derived from the observations. For example, Figs. 12a,b reveal that 


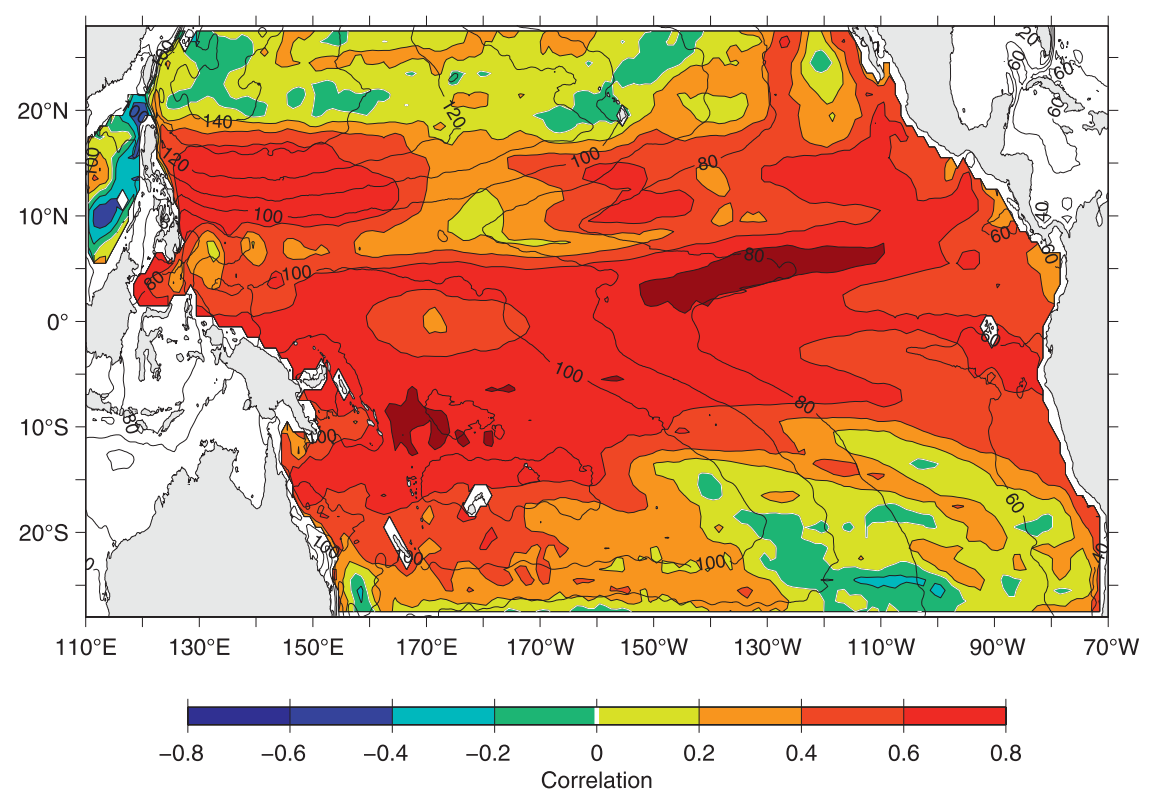

FIG. 11. Map of linear correlation coefficient between the observed and modeled SSH time series in 1993-2009. Black contours indicate the mean SSH field (cm) in the Pacific Ocean from Rio et al. (2011).

the NEC transport circulating in the tropical and subtropical gyres has an increasing trend of 5.4 and $4.4 \mathrm{~Sv}$ over the 1993-2009 period, respectively. Although the observed $T_{\mathrm{NEC}-\mathrm{N}}$ has a larger trend compared to $T_{\mathrm{NEC}-\mathrm{S}}$ shown in Figs. 4a,b, the observed 17-yr trend for the total NEC transport of $8.5 \mathrm{~Sv}(17 \mathrm{yr})^{-1}$ is similar to that from the model. For the NECC transport, the increasing trend of $3.6 \mathrm{~Sv}(17 \mathrm{yr})^{-1}$ from the model agrees favorably with the observed trend of $4.1 \mathrm{~Sv}(17 \mathrm{yr})^{-1}$. With regard to latitudinal position of the tropical gyre, the modeled $Y_{c}$ time series in Fig. 12c reveals a southward migrating trend at a rate smaller than but consistent with that detected in Fig. 4c.

For a further comparison between the model and observations, we plot in Fig. 13a the distribution of the modeled trend in $u H$. Compared to the observed distribution shown in Fig. 5, good agreement can be seen in the NEC and NECC regions south of $\sim 20^{\circ} \mathrm{N}$. Specifically, both the model and observations show positive $u H$ trends in the $2^{\circ}-5^{\circ} \mathrm{N}$ and $13^{\circ}-20^{\circ} \mathrm{N}$ bands and negative $u H$ trends in the $5^{\circ}-13^{\circ} \mathrm{N}$ band in between. The appearance of these alternating bands, as we noted in section 2, reflects the combined effects of the southward migration of the tropical gyre and the strengthening of the NEC and NECC over the 1993-2009 period. Given that our adopted model is purely wind driven, this comparison confirms the importance of wind forcing in generating the regional sea level and circulation trends detected in the western tropical Pacific Ocean.
From comparing Figs. 13a and 5, it is also clear that the model is unsuccessful in simulating the observed $u H$ trends north of $\sim 20^{\circ} \mathrm{N}$. As seen in Fig. 6, this northern region is occupied by the surface-trapped Subtropical Countercurrent (STCC), the Kuroshio, and the Kuroshio's recirculation gyre. As explored extensively in previous studies (see, e.g., Qiu 1999; Qiu and Miao 2000, and the references therein), the variability of these currents is governed by dynamical interactions of different vertical modes and cannot be accounted for by the 1/1/2-layer reduced-gravity model used in this study.

\section{Summary and discussion}

Accumulation of the high-precision satellite altimeter data has provided us not only a tool to monitor the rising sea level on the regional scales but also an opportunity to explore the concurrent ocean circulation changes. Over the past $17 \mathrm{yr}$ from 1993 to 2009, a regional sea level rise maximum with trend exceeding $10 \mathrm{~mm} \mathrm{yr}^{-1}$ occupied the northwestern tropical North Pacific Ocean along the boundary of the wind-driven tropical and subtropical gyres. By combining the altimeter-measured SSH data with the climatological upper-ocean layer thickness data, we found that this regionally enhanced sea level rise signal is accompanied by the southward migration and strengthening of the two major zonal currents in the region: the NEC and the NECC. Reflecting the southward migration, the bifurcation latitude of the NEC along the Philippine 

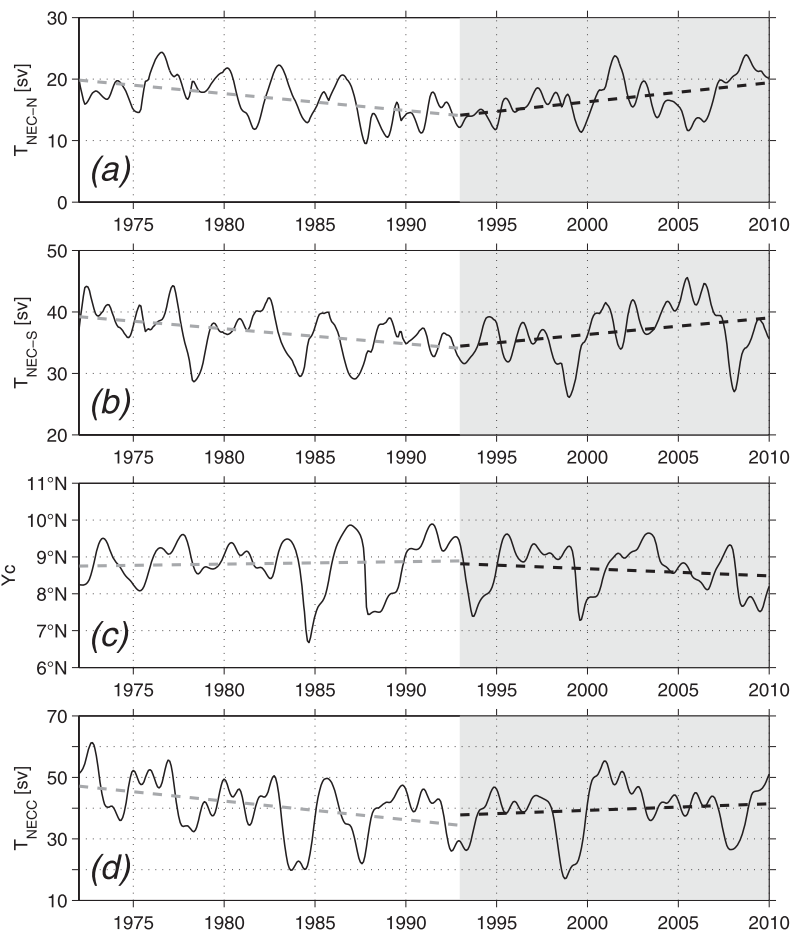

FIG. 12. Time series of (a) $T_{\mathrm{NEC}-\mathrm{N}}$, (b) $T_{\mathrm{NEC}-\mathrm{S}}$, (c) $Y_{c}$, and (d) $T_{\mathrm{NECC}}$ from the wind-driven $1 \frac{1}{2}-$-layer reduced-gravity model. In all plots, the shaded period denotes 1993-2009, black lines denote the low-pass-filtered time series, and black (gray) dashed lines denote the linear trends over the period of 1993-2009 (1972-92).

coast and the center latitude of the tropical gyre were observed to have shifted equatorward by $2^{\circ}$ and $1^{\circ}$, respectively, over the 1993-2009 period. The strengthening, on the other hand, was characterized by a 7-Sv transport increase in the NEC that circulates inside the subtropical gyre and a 1.6-4.1-Sv transport increase in the NEC and NECC that make up the North Pacific tropical gyre. Rather than extending into the midlatitudes, the enhanced, northward-flowing NEC tended to recirculate within the southern subtropical gyre south of $22^{\circ} \mathrm{N}$.

Independent of the satellite altimeter measurements, these long-term position and transport changes in the NEC and NECC were also confirmed by the quarterly repeat hydrographic surveys by JMA along $137^{\circ} \mathrm{E}$. In the tropical region south of $20^{\circ} \mathrm{N}$, the hydrographic surveys revealed that the time-varying temperature signals were confined coherently to the upper-ocean layer above the $12^{\circ} \mathrm{C}$ isotherm and that the thermosteric signals contributed dominantly to the observed maximum sea level rise trend of $>10 \mathrm{~mm} \mathrm{yr}^{-1}$. Because the salinity in the western tropical North Pacific Ocean does not vary monotonically with depth, the time-varying salinity signals were vertically incoherent and their vertically integrated effect

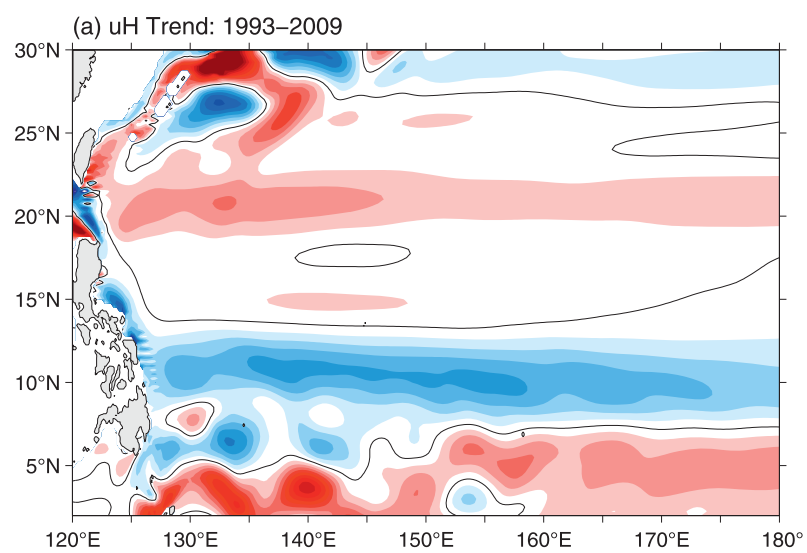

(b) uH Trend: 1972-1992

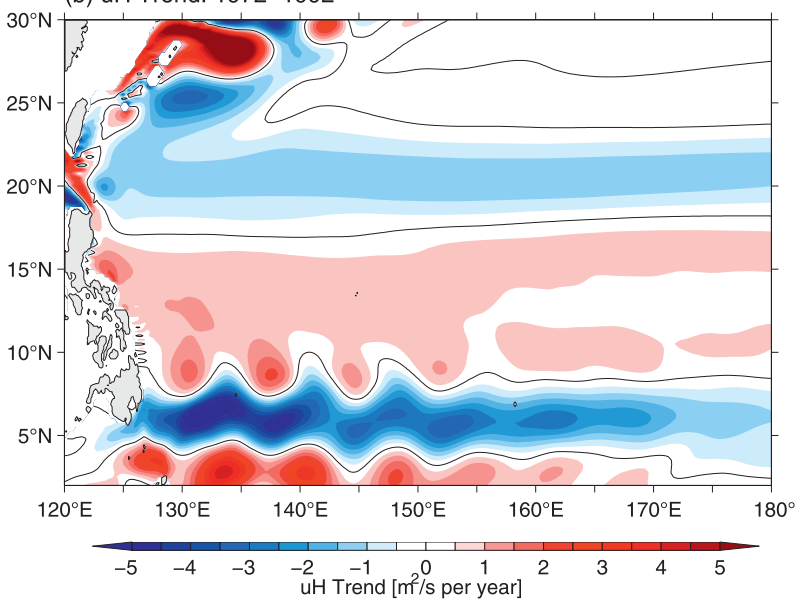

FIG. 13. Linear trend in the zonal transport $u H$ field over the period of (a) 1993-2009 and (b) 1972-92 from the wind-driven 11/2layer reduced-gravity model. Black contours denote $u H=0$.

(i.e., the halosteric signal) had little impact to the observed regional sea level trend.

With the validity of its dynamics in the tropical Pacific Ocean confirmed by the repeat hydrographic surveys, we adopted a nonlinear 11/2-layer reduced-gravity model to quantify the sea level and circulation changes in response to the time-varying surface wind stress forcing. Driven by the ECMWF reanalysis wind data, the model was able to simulate quantitatively the spatial pattern of the sea level trend, as well as the migration and transport changes of the NEC and NECC detected by the satellite altimeter and repeat hydrographic data. The favorable comparison between the model and observations confirm that the regional sea level and circulation trends detected in the western tropical Pacific Ocean in the 1993-2009 period largely reflect the dynamical response to the changing surface wind stress field.

The importance of surface wind forcing can be further appreciated if we look into the circulation changes in the western tropical Pacific Ocean for the period beyond the 

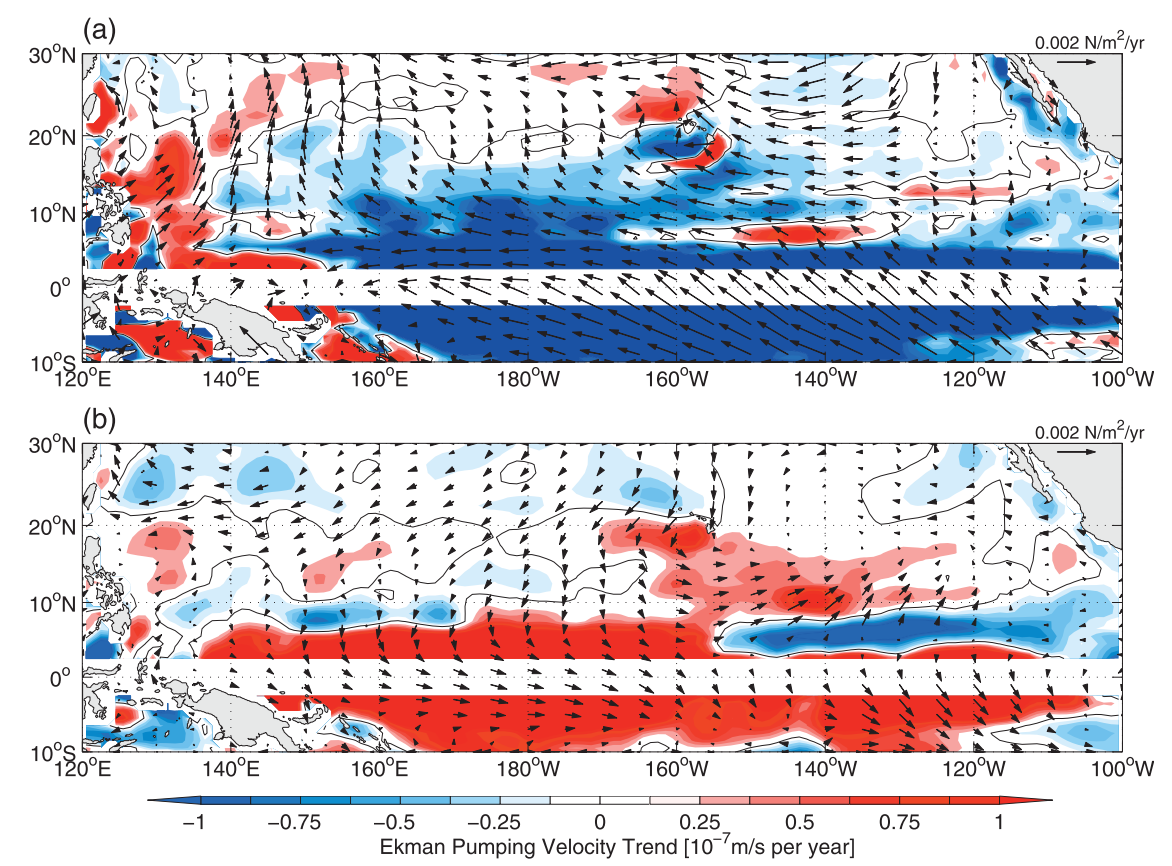

FIG. 14. Linear trends in wind stress (vectors) and Ekman flux divergence $w_{\mathrm{Ek}}=\mathbf{k} \cdot \nabla \times$ $\left(\tau / \rho_{o} f\right)$ (color shading) over the periods of (a) 1993-2009 and (b) 1972-92 based on the ECMWF ORA-S2 reanalysis data. Positive (negative) $w_{\text {Ek }}$ signifies upward (downward) motion at the base of the Ekman layer. Black contours denote $w_{\mathrm{Ek}}=0$.

17-yr satellite altimeter era. By analyzing the tide gauge sea level, sea surface temperature, surface wind stress, and outgoing longwave radiation data dating back to the 1960s, Merrifield (2011) found recently that the early 1990s marked a shift in trend for the oceanic and atmospheric variables in the western tropical Pacific Ocean. For example, in contrast to the increasing trend of $10 \mathrm{~mm} \mathrm{yr}^{-1}$ observed in 1993-2009, the sea level trend based on all available tide gauge records in the western tropical Pacific Ocean had a close to zero trend during the three decades prior to 1992 (see Fig. 6 of Merrifield 2011). This shift in trend at the early 1990s is also evident in the NEC and NECC variability simulated in our wind-driven 11/2-layer reduced-gravity model. As shown in Fig. 12, the NEC and NECC transports had decreasing trends during the 1972-92 period as opposed to the increasing trends after 1993. Similarly, instead of its recent southward migration, the center latitude of the wind-driven tropical gyre had a weak northward migration during the two decades prior to 1993 . These changes in trend can also be verified in Fig. 13b, showing the spatial map of the modeled zonal transport $u H$ trend for the 1972-92 period. Separated by the mean latitude of the tropical gyre along $\sim 8^{\circ} \mathrm{N}$, the $u H$ trend is positive to the north and negative to the south, signaling the weakening of both the NEC and NECC during the 1972-92 period. Notice that the spatial pattern in Fig. 13b is not a simple mirror image of Fig. 13a because the NEC and NECC fluctuated in both their lateral positions and their intensities.

The cause to this shift in the NEC and NECC trends can be sought in the multidecadally modulating surface wind forcing field. In agreement with the analysis of sea level pressure data by Vecchi et al. (2006), the easterly trade winds, or the lower branch of the atmospheric Walker circulation, over the 1972-92 period had a decreasing trend across the tropical Pacific Ocean (see vectors in Fig. 14b). Associated with this decreasing trend in the trade winds, the Ekman flux divergence, $w_{\mathrm{Ek}} \equiv \mathbf{k} \cdot \nabla \times\left(\tau / \rho_{o} f\right)$, in the western tropical Pacific Ocean had a strong positive trend in the $2^{\circ}-6^{\circ} \mathrm{N}$ band, a negative trend in the $6^{\circ}-12^{\circ} \mathrm{N}$ band, and another positive trend in the $12^{\circ}-18^{\circ} \mathrm{N}$ band (see color shading in Fig. 13b). As a positive (negative) Ekman flux divergence decreases (increases) the SSH, the southern pair of positive and negative $w_{\mathrm{Ek}}$ forcing induces anomalous westward geostrophic flows and is responsible for the negative $u H$ trend, or a weakening NECC, in the $4^{\circ}-8^{\circ} \mathrm{N}$ band shown in Fig. 13b. Similarly, the negative-positive pair of the $w_{\mathrm{Ek}}$ forcing north of $6^{\circ} \mathrm{N}$ produces anomalous eastward geostrophic flows and is responsible for the positive $u H$ trend, or a weakening NEC, in the $8^{\circ}-16^{\circ} \mathrm{N}$ band shown in Fig. 13b.

The decreasing trend in the trade winds across the tropical Pacific, however, reversed at the beginning of 1990s (e.g., Feng et al. 2010; Merrifield 2011). As shown 
in Fig. 14a, the strengthening trade winds induced a broadscale negative Ekman flux divergence trend in the tropical North Pacific Ocean. With the maximum negative Ekman flux divergence occurring along $\sim 5^{\circ} \mathrm{N}$, the resultant zonal geostrophic flows have a positive trend south of $5^{\circ} \mathrm{N}$ and a negative trend north of $5^{\circ} \mathrm{N}$, as indicated in Fig. 13a.

We have in the present study focused on the multidecadal SSH signals in the northwestern tropical Pacific Ocean. Similar SSH signals have been detected in the southwestern tropical Pacific Ocean (recall Fig. 10) and the time-varying surface wind forcing was again found to be an important contributor (Qiu and Chen 2006; Sasaki et al. 2008; Timmermann et al. 2010). It is important to emphasize that understanding the wind-forced, multidecadal SSH changes provides a means for reducing the "noise" relating to the ocean dynamics and affords the possibility of quantifying subtler sea level signals that are driven by thermodynamics, air-sea interaction, and oceanic mixing (Bindoff et al. 2007).

Compared to the tropics, the temperature trends in the subtropical region north of $20^{\circ} \mathrm{N}$ are less vertically and meridionally coherent. As a result of this change in the temperature trend characteristics, the regional sea level and the associated upper-ocean zonal transport north of $20^{\circ} \mathrm{N}$ are dominated by zonally aligned trends with small meridional scales ( $\sim 250 \mathrm{~km}$; recall Fig. 5). Although not pursued in this study, it would be interesting for future research to clarify the causes of these small-scale sea level and zonal current trends characterizing the subtropical western North Pacific Ocean.

Acknowledgments. This study benefited from discussions with Mark Merrifield, Axel Timmermann, and Gabriel Vecchi. In-depth comments made by Nathan Bindoff and Billy Kessler helped improve an early version of the manuscript. We thank Magdelena Balmaseda and Jim Potemra for providing the ECMWF ORA-S3 surface wind stress data via the IPRC's Asia-Pacific Data Research Center. The merged satellite altimeter data was provided by the CLS Space Oceanography Division as part of the Environment and Climate EU ENACT project and the repeat hydrographic data along $137^{\circ} \mathrm{E}$ by the Japan Meteorological Agency. This research was supported by Grant N00014-10-1-0267 of ONR and by Contract 1207881 from JPL as part of the NASA Ocean Surface Topography Mission.

\section{REFERENCES}

Balmaseda, M. A., A. Vidard, and D. L. T. Anderson, 2008: The ECMWF Ocean Analysis System: ORA-S3. Mon. Wea. Rev., 136, 3018-3034.

Bindoff, N. L., and Coauthors, 2007: Observations: Oceanic climate change and sea level. Climate Change 2007: The Physical
Science Basis, S. Solomon et al., Eds., Cambridge University Press, 385-432.

Capotondi, A., and M. A. Alexander, 2001: Rossby waves in the tropical North Pacific and their role in decadal thermocline variability. J. Phys. Oceanogr., 31, 3496-3515.

Carton, J. A., B. S. Giese, and S. A. Grodsky, 2005: Sea level and the warming of the oceans in the Simple Ocean Data Assimilation (SODA) ocean reanalysis. J. Geophys. Res., 110, C09006, doi:10.1029/2004JC002817.

Church, J., N. J. White, R. Coleman, K. Lambeck, and J. X. Mitrovica, 2004: Estimates of the regional distribution of sea level rise over the 1950-2000 period. J. Climate, 17, 2609-2625.

Ducet, N., P.-Y. Le Traon, and G. Reverdin, 2000: Global high-resolution mapping of ocean circulation from TOPEX/ Poseidon and ERS-1 and -2. J. Geophys. Res., 105, 19 47719498

Feng, M., M. J. McPhaden, and T. Lee, 2010: Decadal variability of the Pacific subtropical cells and their influence on the southeast Indian Ocean. Geophys. Res. Lett., 37, L09606, doi:10.1029/ 2010GL042796.

Kashino, Y., N. Espana, F. Syamsudin, K. J. Richards, T. Jensen, P. Dutrieux, and A. Ishida, 2009: Observations of the North Equatorial Current, Mindanao Current, and the Kuroshio Current system during the 2006/07 El Niño and 2007/08 La Niña. J. Oceanogr., 65, 325-333.

Kessler, W. S., 1990: Observation of long Rossby waves in the northern tropical Pacific. J. Geophys. Res., 95, 5183-5217.

Kim, Y. Y., T. Qu, T. Jensen, T. Miyama, H. Mitsudera, H.-W. Kang, and A. Ishida, 2004: Seasonal and interannual variations of the North Equatorial Current bifurcation in a highresolution OGCM. J. Geophys. Res., 109, C03040, doi:10.1029/ 2003JC002013.

Kobashi, F., and H. Kawamura, 2002: Seasonal variation and instability nature of the North Pacific Subtropical Countercurrent and the Hawaiian Lee Countercurrent. J. Geophys. Res., 107, C03185, doi:10.1029/2001JC001225.

Köhl, A., and D. Stammer, 2008: Decadal sea level changes in the 50-year GECCO ocean synthesis. J. Climate, 21, 1876-1890.

Lee, T., and M. J. McPhaden, 2008: Decadal phase change in largescale sea level and winds in the Indo-Pacific region at the end of the 20th century. Geophys. Res. Lett., 35, L01605, doi:10.1029/ 2007GL032419.

Le Traon, P.-Y., F. Nadal, and N. Ducet, 1998: An improved mapping method of multisatellite altimeter data. J. Atmos. Oceanic Technol., 15, 522-534.

Locarnini, R. A., A. V. Mishonov, J. I. Antonov, T. P. Boyer, H. E. Garcia, O. K. Baranova, M. M. Zweng, and D. R. Johnson, 2010: Temperature. Vol. 1, World Ocean Atlas 2009, NOAA Atlas NESDIS 68, 184 pp.

Lukas, R., E. Firing, P. Hacker, P. L. Richardson, C. A. Collins, R. Fine, and R. Gammon, 1991: Observations of the Mindanao Current during the Western Equatorial Pacific Ocean Circulation Study. J. Geophys. Res., 96, 7089-7104.

Merrifield, M. A., 2011: A shift in western tropical Pacific sea level trends during the 1990s. J. Climate, 24, 4126-4138.

Qiu, B., 1999: Seasonal eddy field modulation of the North Pacific Subtropical Countercurrent: TOPEX/Poseidon observations and theory. J. Phys. Oceanogr., 29, 2471-2486.

— , and T. M. Joyce, 1992: Interannual variability in the mid- and low-latitude western North Pacific. J. Phys. Oceanogr., 22, 1062-1079.

_, and R. Lukas, 1996: Seasonal and interannual variability of the North Equatorial Current, the Mindanao Current and the 
Kuroshio along the Pacific western boundary. J. Geophys. Res., 101, 12 315-12 330.

, and W. Miao, 2000: Kuroshio path variations south of Japan: Bimodality as a self-sustained internal oscillation. J. Phys. Oceanogr., 30, 2124-2137.

— surface height field of the South Pacific Ocean: Observations and causes. J. Phys. Oceanogr., 36, 1751-1762.

$\longrightarrow$, and — 2010: Interannual-to-decadal variability in the bifurcation of the North Equatorial Current off the Philippines. J. Phys. Oceanogr., 40, 2525-2538.

Rio, M. H., S. Guinehut, and G. Larnicol, 2011: New CNESCLS09 global mean dynamic topography computed from the combination of GRACE data, altimetry, and in situ measurements. J. Geophys. Res., 116, C07018, doi:10.1029/ 2010JC006505.

Roemmich, D., and J. Gilson, 2001: Eddy transport of heat and thermocline waters in the North Pacific: A key to interannual/ decadal climate variability? J. Phys. Oceanogr., 31, 675-687.

- _ — R. Davis, P. Sutton, S. Wijffels, and S. Riser, 2007: Decadal spinup of the South Pacific subtropical gyre. J. Phys. Oceanogr., 37, 162-173.
Sasaki, Y., S. Minobe, N. Schneider, T. Kagimoto, M. Nonaka, and H. Sasaki, 2008: Decadal sea level variability in the South Pacific in a global eddy-resolving ocean model hindcast. J. Phys. Oceanogr., 38, 1731-1747.

Timmermann, A., S. McGregor, and F.-F. Jin, 2010: Wind effects on the past and future regional sea level trends in the southern Indo-Pacific. J. Climate, 23, 4429-4437.

Toole, J., E. Zou, and R. Millard, 1988: On the circulation of the upper waters in the western equatorial Pacific Ocean. Deep-Sea Res., 35, 1451-1482.

Tsuchiya, M., 1975: Subsurface countercurrents in the Pacific Ocean. J. Mar. Res., 33 (Suppl.), 145-175.

Vecchi, G. A., B. J. Soden, A. T. Wittenberg, I. M. Held, A. Leetmaa, and M. J. Harrison, 2006: Weakening of tropical Pacific atmospheric circulation due to anthropogenic forcing. Nature, 441, 73-76.

Willis, J. K., D. P. Chambers, C.-Y. Kuo, and C. K. Shum, 2010: Global sea level rise-Recent progress and challenges for the decade to come. Oceanography, 23, 26-35.

Yu, Z., J. P. McCreary Jr., W. S. Kessler, and K. A. Kelly, 2000: Influence of equatorial dynamics on the Pacific North Equatorial Countercurrent. J. Phys. Oceanogr., 30, 3179-3190. 